\title{
Management of Colleges with Innovative Trends: Indicators, Criteria and Success
}

\author{
Sevda Hidayet Gizi Akhundova \\ Ph.D. Researcher \\ Khazar University \\ Azerbaijan
}

\begin{abstract}
Educational reforms as innovative activities play important role in the development of college students' and college staff's scientific, cognitive, psychological and social skills. The role of innovations in education and education management involves a considerable complexity, as a whole process. Thus, innovations and their application are the necessary conditions for implementing creativity-driven ideas, including the targeted activities of the entire college staff to achieve the strategic educational goals.

Under the general outlook and general methodology, the overall integrative relations of innovatiions with the quality management of the educational institutions, colleges in particular, needs to be properly assessed, and the trends and factors determining the phenomenon of this intercation between innovative educational activities and organizational reinforcement to be determined. These issues require to identify the necessary criteria for evalutaion of the success indicators, leading to the quality assurance through the advanced practices and activities in the assessment of colleges' overall productivity. Clearly, the developmental factors for the assessment criteria will be the vital issues in the contemporary education processes. On the basis of this, there are opportunities to challenge and apply innovative proposals that are more or less protected by the educational organizations.The article tries to shed light on the processes of interaction of managerial innovations in the college type institutions and their major indicators and criteria for evaluations.
\end{abstract}

Keywords: innovation concept in educational colleges, notional apparatus of a college innovation, resourse patterns of college innovations, implementation stages of innovations, college environment, characteristics and management of educational innovations

\section{Introduction}

Today, the scholars of different fields of study try to put forward their ideas on possible interrelations of innovations and their various parameters of management, including success stories, managerial peculiarities and feasible indicators. "Despite broad interest and a vast literature, understanding of innovative behavior in organizations remains relatively undeveloped."'[1- p.1] . No doubt, that a set of implications related to innovations and their future perspectives is not monotonous, that is why its concept based on some creativity but not limited to this only, is often connected with the individual or group endeavors."Since Schumpeter's seminal work on the central role of innovation on economic development in 1911, research on innovation has continuously grown and has spilled over to many fields of inquiry including sociology, psychology, business administration, and public management. The vast and expansive research on innovation spans multiple levels of analysis (individual, team, organization, industry, economy) and probes multiple aspects of this complex phenomenon antecedents, processes, typologies, attributes, consequences). The breadth of innovation research and diversity of the fields of knowledge it draws from have resulted in many different conceptualizations and measurements of innovation, making even a cursory understanding of the phenomenon increasingly challenging" [3-p. 424].

\section{Analyses of the innovation concept in educational colleges}

Historically, the types of innovations and their specific features, structural analyses and principles of their applications are quite different. Nevertheless, there are a set of common features, that can bring the various ends into the conformity of their definitional determination; that is why it is not an accidental grasp that many of the scholars agree on the definition of Damanpour (1991), which looks like as the following: "An innovation can be a new product or service, a new production process technology, a new structure or administrative system, or a new 
plan or program pertaining to organisational members. Since this definition accommodates different forms of innovation, it allows us to minimize the possibility of selection biases rooted in definition issues." [5]

Eventually, this definition does not only embrace the innovations in economic, engineering and technological spheres, but it is also all embrasive in terms of social sciences and humanities, in educational spere, in particular. Reflecting the administrative and managerial facets, this conceptual approach seems more comprehensive, where it avoids all ambitions in defining the notional apparatus of "innovation".

In terms of functions and content of activities, colleges are different in the world because it is equivocal to tertiary education in some European countries and in the USA whereas it is only indication of technical or vocational schools in Azerbaijan; that is why while analysing the qualitative features and functional terms of the colleges, we more consider the models of world practices, rather than the local patterns. Terminologically "a college" (Latin: collegium) is an educational institution or a constituent part of one. A college may be a degree-awarding tertiary educational institution, a part of a collegiate or federal university, or an institution offering vocational education." [6] So, all we speak about the universities or institutes are similar with college in terms of higher education.

Clearly, innovative personnel of the colleges that demand additional aid from the community groups, entire society and individuals (considering that colleges mainly work on the principles of donations by the governments if we exclude the private ones) require some advocacy works within and outside the innovation groups. This may facilitate to easing the managerial profiles of the educational innovations undertaken for further processing because such type of nuances, sooner or later, turn up to benefit not only a group of people in this or in that college, but pursue the goals for entirely advancement of in-county educational system or processes with possibilities to be excelled and applied outside institutions in the world. "Instead of pursuing autonomous strategies of innovation types, managers are advised to pursue synchronous strategies of innovations as firms' innovative performance depends on how well innovations of different types advance organizational goals together, not on how each contributes alone." [3-p.448]

\section{Notional apparatus of a college innovation.}

By the existing literay resources and our own experience we have identified the following elements or environmental patterns which may serve as an overall model serving for the precise notional apparatus of a college innovation.. These are:

1. Getting new knowledge based on existing one with individual, group or collective pursue;

2. Making, critical, and creative thinking, analysis, synthesis and performance;

3. Assessing cognitive operations such as evaluation in each steps of the project;

4. Independent work of the project staff in the pre-thought stage and a thorough content analyses of the organized work, levels of logical, critical and creative activities;

5. Development of creative thinking, independent learning and working;

6. A question of new knowledge and all its paradigms;

7. Presentation of the up-to-date and current requirements for organizing fruitful and innovation-driven work within a comprehensive time limit;

8. Application of relevant demonstration forms of educational patterns or behaviors that meet the modern and soesific requirements;

9. Reflection and realization of future personality-based and professional development activities, and the well structured attained idea;

10. Consideration of the modern trends of development of the relevant innovation.

\section{Resource patterns of college innovations}

The question of management of innovations is one the widely worked-out areas. Nevertheless, the ideas referring to the analyses of this problem vary from case to case.

There are different reasons behind that: (1) Existence of various types of individual features, profiles of the institutions implementing the innovative practices; (2) Environmental differences in terms of economic, social and cultural domains of the organisations, and (3) Innovative -driven traits and the levels of enthusiasm and other intrinsic motivations, (readiness, satisfaction of the units, etc.) to realize the innovations .

All these factors may be detailed in two distinct domains:

1. Resourcefulness and functionality of innovations; 


\section{Educating behaviorial patterns caused by innovations.}

The problem of resourcefulness of the colleges and teachers' readiness for practical innovation activity is still relevant today. There are a number of reasons preventing implementation of innovations in pedagogical activity. The main, in our opinion, is absence of educational system, which provides the necessary knowledge for the implementation of innovations as beginners, and lack of experienced teachers. Necessary changes in education cannot occur if a college staff will not seek to improve their professional activities. The time and effort required to bring new ideas and the new ways of educational innovations have become a practice largely depending on an extent of readiness and ability of the college staff to change their activities, mastering innovations and becoming co-creators of the new innovative practices. In this regard, a particular importance is given to the problems of introduction the staff into the different traditional and innovative practices in educational dimension, innovative learning technologies and ensuring appropriate levels of readiness of college resources for innovative activities. The gained practices in this sphere make a witness that, those with a short-term educational paractice usually tend to misunderstand or not understand the formula of innovation, its role and function; that is why, while analysing the resource of a college, a special attention should be given to the levels of pedagogical staff and their experience.

It is also essential to find out the reasons of why there exists a vacuum of innovative practices or desire of preventing them to happen. To our opinion, there are some major assumptions around this question which can fall under the following categories:

1.Innovations may not have a place because of inadequate financing;

2.Insufficient competence (ignorance, in particular) may have a place to impede the ways of their further implementation;

3. Deficiency of social order such as the profiles taught in the colleges may not be relevant to the community groups;

4. The possible and traditional pedagogical conservatism may totally supercede to stimulate the innovation.

In the likely cases, creating an atmosphere of openness, full awareness of all subjects of the educational process may serve as significant solutions to this problem

Along with these, in fact, colleges with innovative inclination may also much easily cope with .process of behavioral patterns of the college staff and students in everyday life. Evidently, the contemporary outlook of college human resources may facilitate to an increased level of interpersonal relations. No doubt that, the advancement of technical and educational resources here makes the college staff be greatly pride of the achievements gained by them, either individually or cooperatively. It also creates further challenges to the stronger developmental trends. Unfortunately, nowadays there are less works done in this practice, which may serve as thorough analyses of interrelations between innovations and behaviorial patterns of the college staff for further increasing the pedagogical and organization dimensions. That is why we leave this question open for now for further researches.

\section{Stages of implementation of innovative ideas in college environment}

This matter is highly appreciated not only by the side of theorists, as well as by the entrepreneurs, organisations and stakeholders. Thoroughly well thought out models and precisely identified stages of innovation implementation are firm guarantees for further success history. From this point of view the stages can be divided into the following set of conditions and activities:

\section{Accumulation of theory and practice on an individual or group level.}

By opinion of Richard Wolfe, the stages of accumulation of innovation covers the following substages: "1) lack of specificity concerning the innovation stage upon which investigations focus; (2) minimal consideration given to innovation characteristics; (3) research being limited to single organizational-type studies, and (4) researchers limiting their scope of inquiry by working within single theoretical perspectives. After these barriers are discussed, research approaches to counter each, and thus, to contribute to more generalizable research, is suggested. The relevance of the barriers and of suggested recommendations to each of the research streams is noted." [1- p. 414]

2. Work outs and mobilization of individual or collective resources

Any type of innovative behavior or idea should be linked to the mobilization force of each individual and turn out to assume a new quality of common practice for everybody. Otherwise, norming and forcing of the 
innovations in the colleges cannot turn out to be a success story, may stay as sporadically and routinely chosen option.

\section{Verification with administration}

Innovation happening should get sufficient support and help by the authorities of the college and government. In other case, it will face a lot of difficulties at least in the projects demanding the elements of institualisation.

4. Short time or temporarily non-expanded experimental pilot programmes;

From this viewpoint, the "perceptions of visibility are significant for current usage but not for future use intentions. This result suggests that while the omnipresence of a technology may compel potential adopters to utilize it in the near term, such an effect may not be sustained after initial usage. The significant effect of visibility is also entirely consistent with the nature of the innovation." [2-p.570]

5. Full expansion and investment;

When the innovation project is tested and become ready for future vast implementation, it needs an expansion plan and the relevant investment plan. "The often paradoxical relationship between investment in information technology and gains in productivity has recently been attributed to a lack of user acceptance of information technology innovations. Diverse streams of research have attempted to explain and predict user acceptance of new information technologies. A common theme underlying these various research streams is the inclusion of the perceived characteristics of an innovation as key independent variables. Furthermore, prior research has utilized different outcomes to represent user acceptance behavior." [2- p. 557] So, any model of innovation "requ-ires at least two essential conditions: recognition sequence of the innovation process, and increased financial investment in science (as science is becoming more and more expensive). Thus, the economic context of understanding innovation is crucial for each research project." [4-p.56]

6. Implementation -considering the social and cultural peculiarities, environment and socialization of the staff working on innovative package, for example, more indifferent person changes into the most active one .

7. Management of college innovations.

This stage is the most essential period for the success history and achievements. Would it be even the most challenging innovative project, once it is not supported by strong management features, it may face the risks and failure.

\section{Characteristics and Management of Educational Innovations in Colleges}

Generation of ideas for the innovations in colleges includes the multilateral management stages including their adoption, adaptation, investment and patenting. This stage, from one side is connected with its commercialization, but from another side, it includes conceptualization and development in management processes. However, " the process of generation of managerial innovation, however, has not been examined specifically until recently." [2-p.432]

Unlike the economic and pure industrial innovations, there are some distinctive peculiarities of educational innovations immanent to this sphere. Educational innovations are more (1) corporative and pretending to exclusive samplings of teaching and learning processes; (2) more targeted to changing and individualistic character because of different levels of knowledge and skills of the college students; (3) highly satisfying in nature for the educational units and for the different ranks of governmental bodies; (4) multidimensional by character, as they are usually applied in groups which are essential for their further adoption, implementation and performance; (5) divergent by their specificity of application in various age groups; (6) and lastly, their readily availability and liability features for the predefined environment.

As it is mentioned, their "usefulness may have a very different connotation in an educational settings, where the technology is being used to facilitate research"[2-p.573], and educational development. Otherwise, comparatively taken, educational innovations may lead to the situation inheriting the most debatable and contradictory sides of innovation where the techno-genetic rationale may not contribute to the improvement of educational settings.

Now, let us look through some important details of innovative ways of college management in Azerbaijan.

This case is vitally important for Azerbaijan., where the college school directors mainly had the BA degrees from the Soviet times (at that time, there did not exist the levels of MA or MBA or MSc degrees in this Republic of Azerbaijan).

Moreover, during the FSU times, the duration of higher schools was 5 years and after the educational reforms at the beginning of 90th, the Magistracy was included into the higher educational system. Consequently, those with BA degrees with 4 years education from the Soviet times automatically were treated as the graduates of the 
relevant field of Magistracy schools. Subsequently, BA degree term was legally decreased to 4 years after the school reforms, and those with BA degrees from the Soviet times continued occupying the positions of directors of various colleges. Of course, it si undeniable fact that, much work, has been done by Azerbaijan Government to carry out some essential educational reforms, especially, in the light of Qulaity Assurance in Azerbaijan colleges. Nevertheless, the current status of Azerbaijan college management still needs additional principal trainings, retraings and support in the fields of school marketing and conceptualization, that without doubt, would be helpful in supporting innovation and opening up these types of schools to the external environment.

Another managerial innovation proposal in the field of teaching and learning may be that, the modern educational theory in colleges to be compliant with the importance of constructivism, which may easily be shifted onto the educational processes reflecting the requiremenst of problem- and project-based learning, as well as other teaching approaches, which may enable the system to overcome the traditional paradigm of a passive learners. Some major strategies in such reforms can be done on the levels of: (a) overall (educational) reform patterns; $;(b)$ peculiarities of the social environments of the colleges with their local communities; (3) reinforcement of the up-tade relations with stakeholder relationships which may easily help to the increase of college efficiency, sustainability and enhance their commercialization activities.

Compilation of the relevant questionnaire concerning the studies of college life to further addressing the findings (shortcomings and preferences) may add the concepts of increasing role of innovative practices in colleges. This usage is currently quite insufficiently built in Azerbaijan colleges, that is why there is not an abundant practice be used in statistical index. This also might serve in further findings of the adequate tools and instruments, as well as methodological support to improve the innovative environment in these institutions.

However, management of innovative practices is not interpreted only in one way because there are also "some tendencies, which underestimate the value and principles of educational innovations, mentioning that, they, at the same time, also lead to global degradation of human environment, facilitating the growth of artificial life. It is also closely connected with the "modern contradictory market economy and its formative role in the technocratic society.

Scientists should more rigorously combine their efforts toward humanistic approaches to new discoveries and innovative practices, and adopt increasingly much pragmatic focus on democratizing innovations and creativity in modern organizations." [4-p.58] It is not debatable that, if any educationional innovation is mismanaged in terms of its audio-visual and informative culture and not be of comprehensive character, it may lead to squzeeng the amount of verbal communications in the educational institutions. For this reason, most of Western resources evaluate such kind of innovative nuances as "the scale of catastrophy" or "psychological disagreement of population or "college community", while trying to put equation marks between the positive trends in establishing the intellectual levels of the community members with their quasi economic stimula.

\section{Succes Indicators of innovation practices}

Indicators for successful innovation are different, and in some cases, they are too much. It shows that the individuality and difference of the fields of researches where the innovations are realised. Some of them are the areas of profit whereas the others are non-profit organisations. It does nt immediately bring to the notion that, non-profit agencies, as NGOs do not pursue the ways of innovative practice. Simply, at least, depending on the complexity of activities and individual features of the organisations, they may also be different. To our opinion, educational innovations, especially in the college sector, may have the following feasible and unfeasible indicators:

1. Unlike the economic sphere, education has specific features, because we cannot immediately apply any innovative idea into all educational institutions, at least because most of innovations in this sphere have not got the immediately feasible indicators;

2. It needs a multifaceted and multistaged coordination- as on a college level, as well as on the ministerial levels;

3. It needs a proof of existing resources from $\mathrm{A}$ to $\mathrm{Z}$, including the preparedness of the necessary human and technical units;

4. Risk assessments are required to eliminate the possible constraints and unforeseen circumstances to avoid the invisible, but far-going dangers in college education;

5. It needs that, a group of college staff to entirely absorb and adapt to the proposed nuances;

6. A clear verification of the existing potential should favor its success potential; 
7. The existing cultural and technical domains of the college staff should be more open to the external critics and the innovative idea, and henceforth, they must not act as "freezing element" of the entire social activity; thus, the innovations in this sector must be free from group interests and not limited to the sole opinion of the college unit;

8. It should comprehensively analysed, including the possible negative attitude from colleagues, in order to be able to stand against the possible psychological pressures by the leaders, community members, stakeholders, etc.

The purpose of these feasible indicators can better serve for Stage Modeling of innovation which are "to determine whether the innovation process involves identifiable stages and, if so, what they are and what their order is."'[1- p.411]

\section{Reference Literature}

Richard Wolfe (Unwersip of Alberta): Organizational innovation: Review, Critique and Suggested Research directions. Journal of Management Studies31:3 May 1994, 0022-2380, pp. 405-431. -P. 27;

Ritu Agarwal: (Information and Management Sciences Department, College of Business, The Florida State University) and Jayesh Prasad Department of MIS and Decision Sciences, University of Dayton, Dayton:

"The Role of Innovation Characteristics and Perceived Voluntariness in the Acceptance of Information Technologies". Decision Sciences, Volume 28 Number 3,Summer 1997. -pp. 557-582;

Fariborz Damanpour, and Deepa Aravind Rutgers University: (USA, City University of New York - College of Staten Island, USA): “ Managerial Innovation: Conceptions, Processes, and Antecedents”, Management and Organization Review 8:2, pp. 423-454;

Eldar Shahgaldiyev:( Associate Professor at Khazar University, Head of Division of Graduate Studies and Research, Associate Vice Rector) Develpoment and Education. "Socio-philosophical analysis of innovations", Magazine Impact Azerbaijan, pp.56-58;

Fariborz Damanpour: "Organizational innovation: a meta analysis of effects of determinants and moderators". Academy of managemet Journal, 34, 1991. pp. 555-90;

College: "Wikipedia": https://en.wikipedia.org/wiki/College 